\title{
PERCEPTION OF HEALTH RISKS: HOW SMOKER STATUS AFFECTS DEFENSIVE OPTIMISM
}

\author{
ANDRÉ HAHN* and BRITTA RENNER \\ Freie Universität Berlin, Psychologie, Health Psychology, WE 10, \\ Habelschwerdter Allee 45, 14195 Berlin. Germany
}

\begin{abstract}
People generally underestimate their risk to come down with a life-threatening disease when comparing themselves to similar others. However, to some extent they do take objective risk status or actual risk behavior into account. The present study examined specific conditions of this phenomenon. It was found that smoker status was associated with a somewhat higher perceived risk of getting lung cancer or smoker's cough or having a heart attack, but not of coming down with other diseases. Still, smokers did not admit that they had an above-average risk for these maladies, thus reflecting defensive optimism. In addition, smokers characterized the behavior of an abstract person, a "risk stereotype", by estimating the number of years of smoking, the daily number of cigarettes, and the cigarettes' nicotine content necessary to be at high risk for lung cancer. There was evidence that smokers used these risk stereotypes as a reference point for evaluating their own relative risk. Smokers also made higher risk estimates if their own behavior approached that of the risk stereotype. On the whole, the results suggest that people use subjective risk factor theories when estimating their own personal health risks.
\end{abstract}

Keywords: Unrealistic optimism; Risk perception; Smoking; Stereotype; Risk behavior; Vulnerability

On the average, individuals hold positive illusions about themselves, the world, and the future, and they harbor deceptive positive selfperceptions, illusions of personal control, and unrealistic optimism about the future. In particular, when it comes to social comparison processes, people tend to make a favorable judgment about their own

\footnotetext{
*Corresponding author. Fax: +49-30-345 00318. E-mail: hahn@psychologie.de. WWW-Page: psychologie.de/hahn.
} 
position within a reference group. Slightly overestimating one's positive characteristics and underestimating the negative ones have been considered to be components of a healthy mind because, among other factors, they help a person to manage stress and to be productive (Taylor, 1989; Taylor and Brown, 1988; 1994). Applied to the perceived likelihood of negative future events, for instance contracting a fatal disease, these positive illusions or perceived invulnerability have become known as "unrealistic optimism" or "optimistic bias" (Perloff and Fetzer, 1986; Weinstein, 1982; 1984; 1989a; 1996). Individuals tend to perceive their own risk of becoming ill or being victimized as lower than that of their peers. For example, asking people how they would judge their chance of getting cancer compared to that of their peers of same sex and similar age (the "average" risk) typically yields in a "below average" estimate (Fontaine and Smith, 1995). This bias may be part of an overall healthy mind, but it poses a problem because people may refrain from taking health precautions. A realistic disease risk perception is commonly seen as a necessary antecedent of the motivation to practice preventive health behaviors. Although risk perception probably does not represent the most important determinant in the motivation process, it can be seen as a factor that sets the stage for contemplating behavior change (Prochaska, 1994; Schwarzer, 1992; 1994; Schwarzer and Fuchs, 1995; Taylor, 1994).

There is a high variability in the subjective estimates of health risks, suggesting that beliefs about susceptibility to harm are not loosely held, and that the likelihood of developing an illness is not conceived of as random. Individuals are aware of differentiating factors that make the occurrence of an illness in one group of persons more likely than in another group. People obviously use such subjective concepts of risk-relevant factors when inferring their own risk. Thus, defensive optimism is a matter of degree. It does not distort reality completely, but rather represents a differential bias. For example, those who are objectively at high risk take this into account and admit that their low-risk peers are better off. Several studies on smoking (Hansen and Malotte, 1986; McKenna et al., 1993; Moore and Rosenthal, 1992; Reppucci et al., 1991; Segerstrom et al., 1993; Strecher et al., 1995; Warner et al., 1994) have noted that 
smokers accurately perceive their health risk to be greater than nonsmokers, suggesting some awareness of their increased risk status. But, nevertheless, they tend to view their own risks as lower than those of an "average smoker" (Boney McCoy et al., 1992; Gibbons et al., 1991) or a "typical smoker" (Lee, 1989). Although smokers may realize that they are at increased risk, they still optimistically distort the magnitude of the health risk posed by smoking.

The present study was designed to replicate these findings in the case of smokers and to add more information about the specific conditions of this effect. People hold implicit theories about the onset of diseases, including, among other factors, various causes (Bishop, 1991). Such implicit theories can be very similar to scientific theories as they are popularized in the media. The upper part of Fig. 1 displays the possible structure and content of such an implicit theory.

Major causes of lung cancer, for example, could be subdivided into environmental (e.g., air pollution), organic (e.g., a genetic predisposition), and behavioral causes (e.g., smoking). Smoking as the most

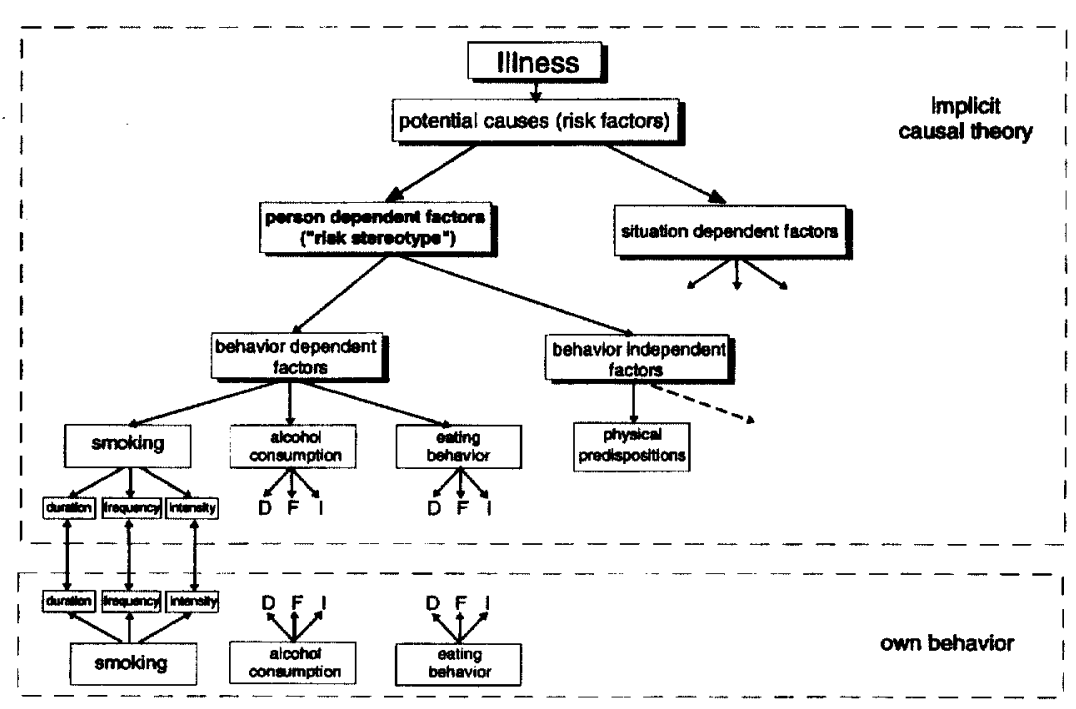

FIGURE 1 Content and structure of an implicit causal theory about the development of a disease (upper part) and the feature matching process as mechanism producing personal risk estimates (lower part). 
conspicuous behavioral cause can be further subdivided into duration (years of smoking), frequency (number of cigarettes per day), and intensity (brand of cigarette). These different causes may have a compensatory effect on each other. For example, individuals who do not live in a polluted environment, who exercise on a regular basis, and who do not have a genetic predisposition might assume that they are only slightly at risk for cancer, even if they smoke. At the behavioral cause level, the subordinate level of this hierarchical implicit theory, another compensatory effect might arise when analyzing one's smoking pattern: Individuals who have smoked for many years might not feel at risk because they smoke only a few cigarettes per day or consume only "light" cigarettes. This latter aspect is the subject of the present study: If smoker status is considered realistically in defensive optimism, how is the behavioral pattern related to this phenomenon? Do smokers, in making a biased risk judgment, consider the duration, frequency, and/or intensity of their smoking?

The theoretical background for this question lies in the existence of an abstract mental image that can be derived of someone who seems particularly likely to be victimized by a health hazard, called a "risk stereotype" (Weinstein, 1980), a "prototypical victim" (Perloff and Fetzer, 1986), or a "victim prototype" (Gibbons et al., 1991). It is examined how a typical lung cancer victim is perceived by smokers, that is, how many years of smoking and how many (strong) cigarettes per day are expected to fit the image of someone who has a high chance of getting lung cancer. Gauging one's own risk, then, can be seen as a cognitive feature-matching process (cf. lower part of Fig. 1). Duration, frequency, and intensity of one's smoking are compared to corresponding attributes of the subjective risk stereotype. High similarity should result in high perceived vulnerability, and low similarity could result in estimates of relative invulnerability. For example, if a person smoked 10 cigarettes a day for 10 years, but estimates that 20 cigarettes a day over 10 years are necessary for a high risk, then he or she would feel relatively safe.

As a rule, one's own personal risk may be perceived as being below average because the risk stereotype, almost by definition, possesses highly pronounced various risk-increasing attributes. This might explain the occurrence of an optimistic bias on the group level, too. 


\section{Research Questions}

The present study attempts to elaborate upon the conditions for defensive optimism. The basic question is whether individuals estimate their health risks too favorably. This replication of "optimistic bias" is essentially a prerequisite for all further questions. The second question is whether people are aware of risk-increasing factors, especially whether they have a stereotype mental image of the behavior of a person at risk. Third, if people believe in relevant risk factors, do they take into consideration their own risk behavior when judging their vulnerability? Fourth, if this holds true, is the effect diseasespecific, or do people generalize their perceived vulnerability to other diseases unrelated to the specific risk behavior? Fifth, do people at risk (e.g., smokers) differentiate their risk appraisals in terms of duration, frequency, or intensity of their risk behavior? Finally, if the perceived risk is the result of a comparison between one's own behavior and the estimated behavior of a person at risk, then the perceived own risk should be greater, the higher the similarity to the risk stereotype is.

\section{METHOD}

\section{Participants}

A total of 154 residents of Berlin, Germany, completed a self-administered questionnaire. Participants were recruited by advertisements in local newspapers announcing a study on health behavior based on a mailed questionnaire. Half of the voluntary participants, who did not receive payment, were female and were on average 38 years old. The youngest participant was 16 years and the oldest 85 years old. Sixteen percent held a minor secondary school degree, 33\% a high school degree, $19 \%$ attended university, and 16\% held an academic title. Sixty percent of the participants were employed, $12 \%$ unemployed, $12 \%$ were on training, and $11 \%$ were homemakers. The sample consisted of 73 smokers $(47.4 \%), 39$ ex-smokers $(25.3 \%)$, and 42 nonsmokers $(27.3 \%)$. Thus, there were more smokers within the sample than could be expected from national norms. In Germany, $37 \%$ of the men and $22 \%$ of the women above the age of 15 smoke 
regularly (Junge, 1995). In Berlin, where the study took place, the prevalence is somewhat higher (especially in the east part of the city), but this is only an insufficient explanation for the relatively high number of smokers within the sample. Unfortunately, there were no further data available to clarify these unusual proportions. Participants who indicated that they had already experienced one or more of the health problems under study were excluded from the corresponding statistical analyses in a risk-specific manner (e.g., nine participants already had a smoker's cough and, thus, were not considered when analyzing this specific risk).

\section{Measures}

\section{Risk Perceptions}

Various estimates were obtained for each of the following six health risks: high blood cholesterol, lung cancer, heart attack, HIV infection, smoker's cough, and liver disease. The present paper deals with the perceived risk of lung cancer and smoker's cough and uses the other risk perceptions only as a reference where needed. There are two comparative methods available to demonstrate unrealistic optimism. The single-item comparative risk measure (direct comparison) was introduced by Weinstein (1980). The other method (indirect comparison), which is less frequently used in research, is based on a difference score between two separate absolute risk estimates for oneself and others (Perloff and Fetzer, 1986). Although the optimistic bias has been observed with both measurement approaches, only few studies have directly compared the two methods (Sutton, 1995; Weinstein, 1989b; Welkenhuysen et al., 1996). The reported correlations between the two methods varied considerably between 0.84 (Weinstein, 1989b) and 0.22 (Welkenhuysen et al., 1996), suggesting a differential effect of measurement method. Therefore, absolute as well as comparative risk judgments were measured. To assess the absolute own risk, participants were asked how likely they thought they would experience each particular health problem (e.g., "What do you think are your chances of developing lung cancer during your life?"). The same question was asked for an average person of one's own age and sex (absolute other's risk, e.g., "How likely do you think it is that someone else - the same sex and age as 
yourself - will develop lung cancer during his/her life?"). Responses were made on 7-point Likert scales ranging from extremely unlikely $(-3)$ to extremely likely $(+3)$. As an indirect comparative risk score, in line with the method used by Perloff and Fetzer (1986), the own risk score was subtracted from the risk score of others.

Following Weinstein's (1982) assessment procedure, the direct comparative risk judgments were also measured by asking: "Compared to other people - the same sex and age as yourself - what do you think are your chances of developing lung cancer during your lifetime?" Responses were given on a 7-point Likert scale ranging from much below average $(-3)$ to much above average (3).

\section{Smoking Behavior}

To assess the risk behavior of smoking, the sample was subdivided into smokers $(n=73)$, ex-smokers $(n=39)$, and nonsmokers $(n=42)$. Smokers and ex-smokers reported in more detail about their behavior by responding to additional questions: duration of smoking ("When did you start smoking?"; "Did you interrupt smoking?"; ex-smokers: "When did you stop smoking?"), frequency of smoking ("How many cigarettes do you smoke each day?"), and intensity of smoking ("The strength of the cigarettes I smoke is ... ultra light [1]/ light [2]/medium [3]/strong [4]/ultra strong [5]"). For smokers, the duration of smoking was calculated by subtracting the person's age from the age of the person at the onset of smoking, and further correcting for time periods of nonsmoking. The same was done for ex-smokers, but using the age when quitting for calculating the duration of smoking.

\section{Risk Stereotype}

To tap the abstract mental image of a potential lung cancer victim, the following instruction was given: "Imagine a person who has a particularly high chance of developing lung cancer. Please characterize the smoking behavior of that person... A person has a high chance of developing lung cancer, if he or she has (a) smoked at least for... (e.g., 10) ... years (duration), (b) smoked at least... (e.g., 20) ... cigarettes each day (frequency), and (c) smoked the following strength of tobacco... ultra light [1] to ultra strong [5]" (intensity). 
The same estimates were obtained for smoker's cough as the target illness.

\section{RESULTS}

First, descriptive statistics are presented that illustrate the degree of defensive optimism in this sample. Table I displays the mean comparative risk judgments for six health risks, that is, respondents positioned themselves with regard to an average person, according to Weinstein's (1982) assessment procedure. Means below zero indicate a tendency to place oneself in a below-average risk group: the lower the mean, the more optimistic the risk judgment. As expected from previous research, all of the health risks were associated with optimistic biases that were significant from zero, as confirmed by simple $t$ tests $(p<0.05)$.

Using the alternative procedure by Perloff and Fetzer (1986) yielded similar results (Table I). Participants perceived their own risk of obtaining any of the six conditions as far below average (absolute risk judgment), whereas they perceived the corresponding risk of others as close to average. This difference was secured by means of a twofactorial repeated measurement analysis of variance (MANOVA), with the two risk judgments as levels of the first within-subjects factor, and the six health risks as levels of the second within-subjects

TABLE I Mean absolute and comparative risk judgments for six health-related problems

\begin{tabular}{|c|c|c|c|c|c|c|}
\hline \multirow[t]{2}{*}{ Risk } & \multicolumn{3}{|c|}{ Absolute risk appraisal ${ }^{\mathrm{a}}$} & \multicolumn{3}{|c|}{ Relative risk appraisal } \\
\hline & $\begin{array}{c}\text { Own } \\
\text { person }\end{array}$ & $\begin{array}{l}\text { Average } \\
\text { person }\end{array}$ & t test & $\begin{array}{c}\text { Perloff } \\
\text { method }\end{array}$ & $\begin{array}{l}\text { Weinstein } \\
\text { method }^{\mathrm{c}}\end{array}$ & $r^{d}$ \\
\hline Lung cancer & -1.11 & -0.15 & $-6.79^{*}$ & -0.97 & $-0.93^{*}$ & $0.48^{*}$ \\
\hline Smoker's cough & -1.18 & 0.23 & $-7.28 *$ & -1.43 & $-1.20^{*}$ & $0.62 *$ \\
\hline Heart attack & -0.73 & 0.10 & $-6.14^{*}$ & -0.84 & $-0.68^{*}$ & $0.42^{*}$ \\
\hline HIV-infection & -1.81 & -0.41 & $-9.63^{*}$ & -1.40 & $-1.78^{*}$ & $0.35^{*}$ \\
\hline Liver disease & -1.77 & -0.56 & $-8.74^{*}$ & -1.21 & $-1.69^{*}$ & $0.41^{*}$ \\
\hline $\begin{array}{l}\text { High blood } \\
\text { cholesterol }\end{array}$ & -0.65 & 0.32 & $-6.73^{*}$ & -0.97 & $-0.74^{*}$ & $0.48^{*}$ \\
\hline
\end{tabular}

Notes. ${ }^{\mathrm{a}}$ Scale $=-3$ (extremely unlikely) to +3 (extremely likely). ${ }^{\mathrm{b}}$ Difference score $=$ own absolute risk subtracted from the absolute risk of the average person. ${ }^{\circ}$ Scale $=-3$ (much below average) to +3 (much above average). ${ }^{d}$ Pearson correlation between the two methods.

$* p<0.001$ ( $p$ values for all correlations are two-tailed) 
factor. The difference between the two risk judgments was considerably high, $F(1,145)=115.74 ; p<0.001$.

Both assessment procedures agreed upon the existence of the expected optimistic bias. But, nevertheless, the only moderate correlations between the two methods propose that they are to some extent divergent. An implication of this insufficient parallelism between the two approaches could be that subjects, when estimating their relative risk, do not simply calculate a difference score to pit their own risk against that of the target, which is an implicit assumption of the method used by Perloff and Fetzer (1986). The algorithm or heuristic used for estimating one's comparative risk may be essential for the constitution of the phenomenon "optimistic bias". Therefore, in the subsequent analyses only the responses elicited by the direct method as described by Weinstein (1982) are considered.

For the two conditions relevant here, lung cancer and smoker's cough, overall defensive optimism is the starting point for the subsequent analyses. Before the participants were asked to judge their vulnerability to these diseases, a screening item asked whether or not they thought that there are certain people who were at high risk for getting lung cancer or smoker's cough. Regardless of their smoking status, all participants agreed upon the existence of a specific risk group (lung cancer [70\%] and smoker's cough [81\%]). On the average, smokers reported that they consumed 16 medium-strong cigarettes every day for about 19 years. Former smokers were abstinent for one year, and they had smoked an average of 16 cigarettes per day for about 22 years. But did smokers consider their own beliefs, in particular their own behavior, when judging their degree of personal vulnerability? Did smokers take their actual risk behavior into account?

The upper three rows of Table II show the mean comparative risk judgments for smoking-related diseases (lung cancer, smoker's cough, and heart attack) separately for smokers, ex-smokers, and nonsmokers. The first of two mixed model analyses of variance (MANOVA) yielded a remarkable main effect of the smoking group factor on the comparative risk judgments for lung cancer, smoker's cough, and heart attack, $F(2,147)=36.37 ; p<0.001$. Subsequent estimates of the simple main effects revealed that $25-45 \%$ of the risk judgment's variance can be accounted for by group membership. 
TABLE II Mean comparative risk judgments for each disease for smokers, ex-smokers and nonsmokers

\begin{tabular}{lcccc}
\hline Risks to appraise & Nonsmokers & Ex-smokers & Smokers & $F$-value \\
\hline Smoking-related risks & $(n=41)$ & $(n=38)$ & $(n=71)$ & \\
$\quad$ Lung cancer & $-1.78^{\mathrm{b}}$ & $-1.60^{\mathrm{b}}$ & $-0.04^{\mathrm{a}}$ & $25.99^{* * *}$ \\
Smoker's cough & $-2.46^{\mathrm{b}}$ & $-2.32^{\mathrm{b}}$ & $0.14^{\mathrm{a}}$ & $53.71^{* * *}$ \\
Heart attack & $-1.32^{\mathrm{b}}$ & $-0.89^{\mathrm{b}}$ & $-0.18^{\mathrm{a}}$ & $9.74^{* * *}$ \\
Smoking-unrelated risks & $(n=41)$ & $(n=38)$ & $(n=70)$ & \\
HIV-infection & $-2.00^{\mathrm{a}}$ & $-1.66^{\mathrm{a}}$ & $-1.51^{\mathrm{a}}$ & $1.76 \mathrm{~ns}$. \\
Liver disease & $-2.05^{\mathrm{a}}$ & $-1.45^{\mathrm{a}}$ & $-1.81^{\mathrm{a}}$ & $1.48 \mathrm{~ns}$. \\
High blood cholesterol & $-0.88^{\mathrm{a}}$ & $-0.84^{\mathrm{a}}$ & $-0.60^{\mathrm{a}}$ & $0.74 \mathrm{~ns}$. \\
\hline
\end{tabular}

Notes. 'Simple main-effects of the grouping factor within each category of the within-group factor. Simple main-effects were calculated for smoking-related risks and smoking-unrelated risks separately. Mean values with different indices $(a, b)$ differ significantly from each other with $p<0.05$ (Scheffé-test).

It is of note that smokers viewed their relative risk as average, whereas nonsmokers and ex-smokers believed that their risk was far below average. The latter two groups did not differ significantly from each other. Smokers viewed themselves as being as vulnerable as average others in terms of future smoking-related health problems. This estimate is, although not different from zero, nevertheless too optimistic, because "the others" as a reference group also includes nonsmokers. Particularly the ex-smokers were too optimistic: On average they had actually smoked longer and just as frequently as the smokers did and had quit smoking about a year before the survey.

The results clearly demonstrate that smokers consider their actual risk behavior when judging their vulnerability for smoking-related health problems. It was further hypothesized that this effect had to be disease specific, that is, smokers were not expected to generalize their perceived vulnerability to other diseases unrelated to smoking.

The lower three rows of Table II display the mean levels of risk estimates for health conditions unrelated to smoking (liver disease, high blood cholesterol, and HIV-infection). The mean relative risk judgments of smokers, ex-smokers, and nonsmokers do not differ significantly with regard to these diseases, $F(2,146)=1.66 ; p=0.194$. Comparable to nonsmokers, smokers showed an equal tendency to be optimistically biased.

However, only smokers judge their relative vulnerability to behaviorspecific health risks much higher than ex-smokers or nonsmokers do (Scheffé-test, $p$ always $<0.001$ ). Participants obviously felt that 
smokers are at some risk for lung cancer, smoker's cough, and myocardial infarct, but not for other ailments. Nevertheless, all mean scores remained below average, that is, in spite of some consideration for objective risk behaviors there is still a high degree of defensive optimism.

While the data analysis so far has dealt with mean levels of subgroups, the next step of analysis takes variation into account. The distribution of the risk estimates for lung cancer showed a remarkable variance within the group of smokers. The whole range of the scale was used when making judgments. It was expected that smokers would further differentiate their risk according to the extent of their smoking behavior. If smokers differentiate their risk in terms of smoking duration, frequency, and intensity, they should have in mind a more or less clear image of the amount of smoking that is necessary to be at risk. Such a risk stereotype is taken as a reference to evaluate one's own risk.

Table III depicts the extent of smoking behavior that participants considered to be sufficient for getting lung cancer and smoker's cough. Smokers thought that if someone smoked about 24 strong cigarettes each day for 14 years they might get lung cancer. The estimated time span to be at risk for smoker's cough is somewhat lower: about 12 years. Former smokers had approximately the same opinion as smokers. The ratings given by nonsmokers could be characterized as more "cautious", in that a smoker who smoked 21 strong cigarettes for about 11 years would bear a substantial risk.

TABLE III Mean perceived sufficient smoking behavior to be at risk for lung cancer and smoker's cough (risk stereotype) as estimated by smokers, ex-smokers and nonsmokers

\begin{tabular}{|c|c|c|c|c|c|c|}
\hline & \multicolumn{3}{|c|}{ Lung cancer $(M, S D)$} & \multicolumn{3}{|c|}{ Smoker's cough $(M, S D)$} \\
\hline & $\begin{array}{l}\text { Duration of } \\
\text { smoking in } \\
\text { years } \\
\text { (Duration) }\end{array}$ & $\begin{array}{c}\text { Smoked } \\
\text { cigarettes } \\
\text { per day } \\
\text { (Frequency) }\end{array}$ & $\begin{array}{l}\text { Strength of } \\
\text { smoked } \\
\text { cigarettes } \\
\text { (Intensity) }\end{array}$ & $\begin{array}{c}\text { Duration of } \\
\text { smoking in } \\
\text { years } \\
\text { (Duration) }\end{array}$ & $\begin{array}{c}\text { Smoked } \\
\text { cigarettes } \\
\text { per day } \\
\text { (Frequency) }\end{array}$ & $\begin{array}{l}\text { Strength of } \\
\text { smoked } \\
\text { cigarettes } \\
\text { (Intensity) }\end{array}$ \\
\hline $\begin{array}{l}\text { Smokers } \\
(n=69-73)\end{array}$ & $14.3(9.6)$ & $23.7(13.2)$ & $3.7(1.0)$ & $12.2(9.4)$ & $22.3(12.9)$ & $3.5(0.9)$ \\
\hline $\begin{array}{l}\text { Ex-smokers } \\
(n=37-39)\end{array}$ & $14.9(8.0)$ & $22.8(11.1)$ & $3.6(0.8)$ & $12.1(8.5)$ & $22.8(10.6)$ & $3.5(0.8)$ \\
\hline $\begin{array}{l}\text { Nonsmokers } \\
(n=38-42)\end{array}$ & $11.1(8.0)$ & $21.2(10.4)$ & $3.6(1.0)$ & $8.5(10.5)$ & $21.2(6.2)$ & $3.6(1.0)$ \\
\hline
\end{tabular}

Note. Sample sizes within smoking status varied due to missing responses. 
But, nevertheless, there were no significant differences between smokers, ex-smokers, and nonsmokers about how an abstract mental image of a high risk person for lung cancer or smoker's cough was created, $F(2,138)=1.28 ; n s$.

Although, on average, smokers seem to have a clear mental image of what is dangerous, there were high interindividual differences within these estimates. That is, each smoker had a different point of reference to estimate his or her own risk. If a smoker, for instance, smoked 10 cigarettes daily, and if 20 cigarettes were estimated as necessary to be at risk, then he or she could feel relatively safe. Another, much heavier smoker could come up with exactly the same conclusion if the necessary behavior to be at risk was estimated somewhat higher.

Two separate hierarchical regression analyses were carried out to test the hypothesis that perceived risk is the result of a comparison process between one's own behavior and one's risk stereotype. Difference scores for each behavioral parameter were computed. For instance, the duration of one's own smoking behavior was subtracted from the stereotype's duration. To examine all possible interaction effects, these relative behavioral parameters were $z$-transformed and then multiplied with each other (Aiken and West, 1991, pp. 43f). The perceived relative susceptibility to lung cancer and smoker's cough served as dependent variables (see Table IV).

These tests revealed two significant effects that were in line with expectations. First, the relative number of cigarettes smoked per day was the strongest predictor for the two comparative risk judgments (lung cancer: $B=-0.64, p<0.01 ;$ smokers' cough: $B=-0.94$, $p<0.001)$. The two regression lines are displayed in Fig. 2 . The "zero" point on the $x$-axis marks the reference point. Here the number of cigarettes a smoker consumed each day equals the number he or she estimated to be dangerous.

Smokers who consumed fewer cigarettes per day than their stereotypes judged their relative risk of developing lung cancer or smoker's cough as below average. However, if the number of cigarettes smoked each day exceeded the estimated dangerous frequency, smokers viewed themselves as more vulnerable in comparison to others. This is the only case where the relative risk judgments of the smokers exceeded the "zero" (average risk) margin. The relative 
TABLE IV Correlations, unstandardized beta weights, and explained variances $\left(R^{2}\right.$ values) for two hierarchical regression analyses predicting relative risk estimates for lung cancer and smoker's cough

\begin{tabular}{|c|c|c|c|c|c|c|}
\hline Step & Predictor $^{\mathrm{a}}$ & $r$ & $B$ & $R^{2}$ & $\begin{array}{c}R^{2} \\
\text { change }\end{array}$ & $\begin{array}{c}F \\
\text { change }\end{array}$ \\
\hline \multicolumn{7}{|c|}{ Lung cancer $^{\text {a }}$ (smokers, $n=61$ ) } \\
\hline 1. & $\begin{array}{l}\text { Duration } \\
\text { Frequency } \\
\text { Intensity }\end{array}$ & $\begin{array}{l}-0.10 \\
-0.44^{* * *} \\
-0.00\end{array}$ & $\begin{array}{c}0.150 \\
-0.641^{* *} \\
0.017\end{array}$ & 0.206 & & $4.94 * *$ \\
\hline 2. & Duration $\times$ Frequency & -0.02 & 0.147 & 0.224 & 0.018 & 1.31 \\
\hline 3. & Duration $\times$ Intensity & 0.03 & 0.085 & 0.228 & 0.004 & 0.28 \\
\hline 4. & Frequency $\times$ Intensity & $0.17^{+}$ & -0.036 & 0.229 & 0.001 & 0.36 \\
\hline 5. & $\begin{array}{l}\text { Duration } \times \text { Frequency } \times \\
\text { Intensity }\end{array}$ & -0.13 & 0.077 & 0.231 & 0.002 & 1.19 \\
\hline \multicolumn{7}{|c|}{ Smoker's cough ${ }^{\mathrm{a}}$ (smokers, $n=59$ ) } \\
\hline 1. & $\begin{array}{l}\text { Duration } \\
\text { Frequency } \\
\text { Intensity }\end{array}$ & $\begin{array}{l}-0.11 \\
-0.55^{* * *} \\
-0.16^{+}\end{array}$ & $\begin{array}{l}0.354^{+} \\
-0.941^{* * *} \\
-0.259\end{array}$ & 0.355 & & $10.09^{* * *}$ \\
\hline 2. & Duration $\times$ Frequency & -0.04 & $0.268^{*}$ & 0.398 & 0.043 & $3.91 *$ \\
\hline 3. & Duration $\times$ Intensity & 0.03 & 0.006 & 0.398 & 0.000 & 0.00 \\
\hline 4. & Frequency $\times$ Intensity & $0.23^{*}$ & -0.123 & 0.402 & 0.004 & 0.35 \\
\hline 5. & $\begin{array}{l}\text { Duration } \times \text { Frequency } \times \\
\text { Intensity }\end{array}$ & $-0.21^{*}$ & 0.166 & 0.408 & 0.006 & 0.50 \\
\hline
\end{tabular}

Notes. $B=$ unstandardized regression coefficient. ${ }^{* * *} p<0.001 ;{ }^{* *} p<0.01 ;{ }^{*} p<0.05 ;{ }^{+} p=0.10$.

${ }^{a}$ Difference scores $=$ own smoking behavior subtracted from stereotype's behavior. Sample sizes for the two analyses varied because of missing responses.

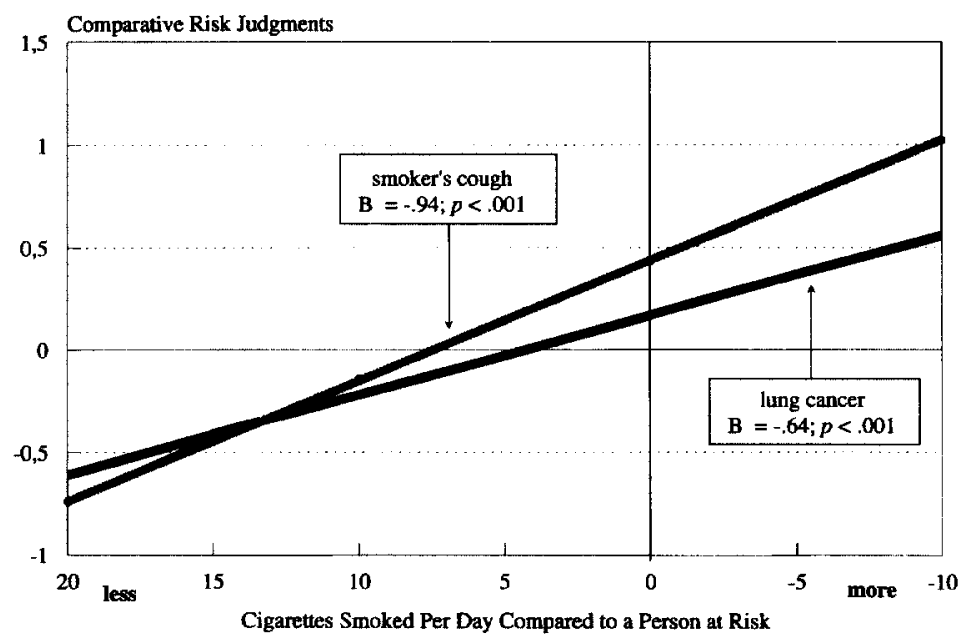

FIGURE 2 Comparative risk judgments as a function of the difference between one's own consumed number of cigarettes per day and the consumption of the risk stereotype (relative frequency). 
behavioral frequency parameter accounted for $20 \%$ and $33 \%$ of the variance of risk ratings.

The frequency effect was further qualified by an interaction between relative duration and relative frequency of smoking behavior ( $B=0.27, p<0.05$ ). This interaction effect occurred only with regard to the risk of smoker's cough (for lung cancer the effect did not reach significance; however, the same pattern resulted).

The grey regression line in Fig. 3 represents the risk estimates of smokers who consumed tobacco for a shorter time span than they believed was dangerous. In this case, the relative number of cigarettes smoked each day was unrelated to the risk judgment for smoker's cough. If, however, smokers consumed tobacco for a relatively long time span compared to their stereotype, there was a strong relation between the relative frequency and the risk appraisal. This is depicted by the black regression line. Here, smokers, although they smoked for a relatively long time, concluded that they were at below-average risk if they smoked only a few cigarettes per day. But the higher the similarity of the number of cigarettes perceived as dangerous, the higher the perceived vulnerability to smoker's cough. In sum, the

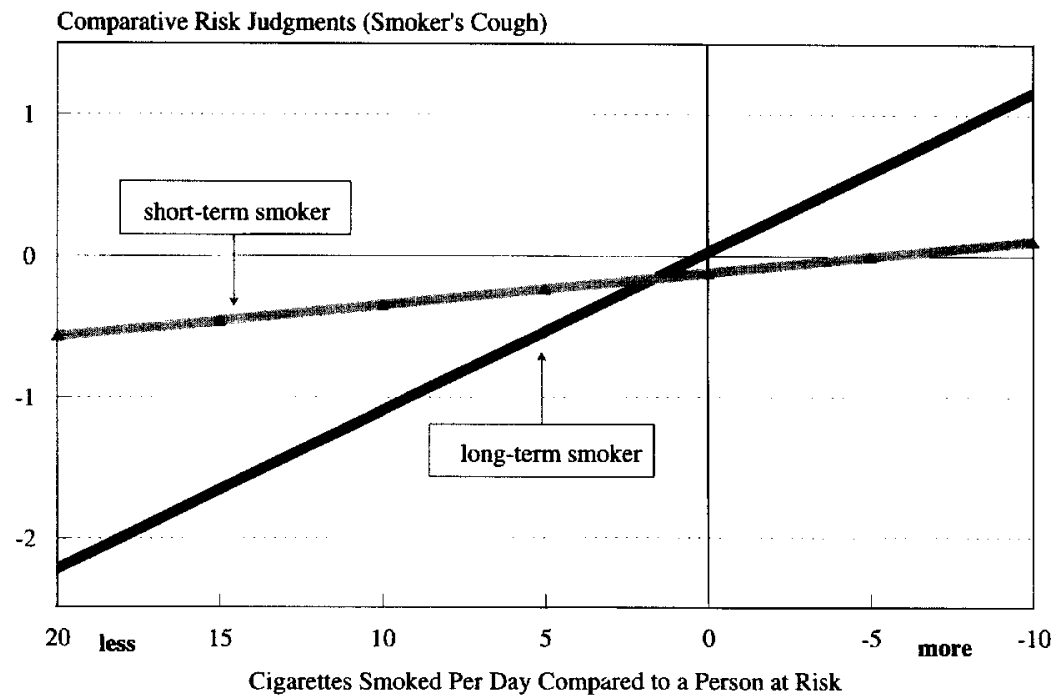

FIGURE 3 Comparative risk judgments for smoker's cough: Interaction of relative frequency and relative duration. 
relative frequency of smoking can be compensated by the relative duration when it comes to gauge one's personal risk.

\section{DISCUSSION}

The present study has confirmed the existence of an optimistic bias when it comes to predicting the likelihood of future diseases. In addition to this replication of earlier findings, a number of more detailed conditions have been found that play a role in defensive optimism. Being objectively more at risk than others is acknowledged to some degree. That is, smokers consider their actual risk behavior when comparing their disease proneness to that of nonsmokers (cf. Gerrard, Gibbons and Benthin, 1996; Hansen and Malotte, 1986; McKenna et al., 1993; Moore and Rosenthal 1992; Reppucci et al., 1991; Segerstrom et al., 1993; Strecher et al., 1995; Warner et al., 1994). However, they still believe that their risk of getting lung cancer or smoker's cough is about average, thus reflecting a strong optimistic bias. On the other hand, nonsmokers judge their risk as extremely low, which might be either accurate or only slightly biased. Ex-smokers make a similar judgment, thus not accepting the fact that they have already practiced a risk behavior that makes them more vulnerable toward adverse health conditions. They give themselves too much credit for quitting smoking by putting themselves at the same low risk level as lifelong nonsmokers. In sum, smoking is considered to pose some risk in one's estimates of future harm, but its effect on one's health is much underestimated. No group admits being at a higher than average risk. Similar findings have been published by Boney McCoy and colleagues (Boney McCoy et al., 1992), as well as in regard to other health hazards, for example the perceived risk of contracting a HIV infection (Gerrard, Gibbons and Bushman, 1996; van der Velde et al., 1994).

There is another more basic and methodological way of interpreting the optimistic risk appraisals of smokers. The result that smokers viewed themselves only as equally vulnerable as average others questions the validity of the measurement procedure to access the relative risk estimates. Do smokers really contemplate an "average other" as comparison targets as worded in the relative risk items? This is 
unlikely, because "the others", as a reference group, are mainly nonsmokers, which is a well-known fact even for smokers. Therefore, smokers who believe to be only at average risk in comparison to all others are not very logical. What might have happened in this case is possibly an example of the representativity heuristic (Kahneman and Tversky, 1972). The participants selected a prototypical representative of the illness category mentioned as part of the item and excluded all other people due to their irrelevance for the category in question (cf. Gibbons et al., 1991; Harris and Middleton, 1994; Perloff and Fetzer, 1986; Weinstein, 1980). A prototypical case of smoker's cough or lung cancer is of course a smoker. Thus, it seems very likely that smokers compare themselves with a typical smoker, and not, as instructed, with an average person. If this holds true, the reported results make much more sense (e.g., smokers viewed themselves on the average as equally vulnerable to smoker's cough as other smokers). These speculations imply that the relative risk estimates of smokers can no longer be labeled as unrealistically optimistic.

The present study goes beyond the mere consideration of objective risk status by further exploring a behavioral profile of smokers. Duration, frequency, and intensity were taken into account. Individuals who engage in a typical risk behavior, such as smoking, differentiate their personal risks as to their behavior profile. This differential selfassessment can be described as the result of a comparison process. To evaluate their own "relative" risk, people use their stereotype conceptions of risk-determining factors, including ideas about the extent of these factors necessary for building up a risk.

Interestingly, only the frequency (number of cigarettes per day) played a role when participants gauged the seriousness of their risk behavior: the strength of the cigarettes seemed irrelevant, since the participants did not assume that smoking light cigarettes was less dangerous than smoking strong ones. Very surprising was the missing relation between duration of smoking and risk judgment. Does this mean that the number of years of smoking was irrelevant for risk estimates? It seems unlikely that the participants equated one year to 20 years of smoking. An explanation could be that smokers depend upon their own duration of smoking when creating their risk stereotype. Smokers who had consumed tobacco for 11 years created a risk stereotype that included 10-and-a-half years of smoking, on 
average. In contrast, long-term smokers who smoked for an average of 27 years estimated the necessary duration for getting lung cancer as more than 19 years. The longer tobacco is consumed, the longer the estimated duration necessary for forming a risk. The implication of this "adjustment effect" is that the difference scores between one's own smoking duration and the risk stereotype's duration are nearly equal for long-term and short-term smokers. Thus, long-term smokers seem to behave in a self-protective manner because their "self-created" stereotypes are as dissimilar to them as the stereotypes of short-term smokers. This can be interpreted as a distortion that helps to keep the individual at a safe distance. To protect oneself from threat, risk stereotypes are established by creating a mental image of a prototypical person with a considerably high risk for lung cancer that is beyond one's own risk behavior. This is another possible way of maintaining and defending optimism (Schwarzer, 1994). There is some evidence for this interpretation from a study conducted by Gibbons and colleagues (1991), who demonstrated that for smokers the image of a typical smoker changed over time, depending on the individual smoking behavior. This image held by smokers became less positive and less similar to the self when they quit smoking. There were similar findings in a more recent study among college freshmen (Gibbons and Gerrard, 1995).

A limitation of the present study lies mainly in its cross-sectional nature and in the self-report data. It would be advantageous to verify the reported behaviors by observational data. Moreover, more knowledge could be gained if variations in behaviors and risk stereotype formation could be documented (cf. Gibbons et al., 1991). For example, it would be of note if individuals extend the frequency and duration parameters of their stereotype as they continue smoking more cigarettes for a longer time span. In contrast, those who cut down on smoking might also be inclined to reduce their stereotype's levels of smoking. This would provide further proof for the hypothesized operative mechanism of defensive optimism. So far, this study has elaborated on the cognitive procedures that may play a role in the way individuals distort their perception to attain positive illusions about their health.

Another limitation of this study concerns the relation between the two commonly used methods of detecting an optimistic bias. Besides 
the agreement between the two methods that there is an optimistic bias, the only moderate interrelations of the approaches suggest that they are not interchangeable. Given the existence of uncertainties about the psychometric merits and the psychological meaning of the two ways used to assess optimistic bias, the search for the origin of unrealistic optimism is at the very last more complicated. Therefore, the question of which method should be used is a fundamental issue for further research.

Another intriguing question is why many smokers quit, if positive illusions are so paramount. Do they quit for reasons other than health threats, or are other psychological determinants responsible for such a life-changing decision? It has to be taken into account that optimistic bias is not a constant parameter, but changes over time and with respect to some circumstances. For example, it has been found that individuals experience a time-out from their illusions when they are more frank and honest with themselves (Taylor and Brown, 1988; 1994).

Illness can create a window of realism that lets people face the world more accurately. They reflect on their shortcomings and behavioral deficits, which makes them more prone to contemplate behavioral change. Further, in a predecisional phase when they are characterized by a deliberative mind set, they carefully appraise alternative goals and weigh the pros and cons of different actions. In the postdecisional phase when they are characterized by an implemental mind set, they may be more optimistic about themselves and harbor positive illusions in service of the motivation needed to attain their goals, as experimental studies suggest (Taylor and Gollwitzer, 1995). This has not yet been shown for health behavior change in general, nor for smokers in particular.

Further studies might want to examine whether defensive optimism really reduces motivation to take health precautions and, if so, to what degree. This could be achieved by embedding the optimistic bias paradigm into a more comprehensive framework of healthrelated cognitions where functional optimism has a place as well (Schwarzer, 1994). Functional optimism refers to the operative power of self-beliefs when it comes to setting prevention goals, making plans for quitting risk behaviors, and adopting health behaviors. In the health behavior change process, unrealistic risk perception may 
set the stage for other health-related cognitions, including outcome expectancies and optimistic self-beliefs (Schwarzer and Fuchs, 1995).

\section{Author Notes}

The authors would like to thank Frederick X. Gibbons for his helpful suggestions regarding a preliminary version of this paper.

\section{References}

Aiken, L.S. and West, S.G. (1991). Multiple regression: Testing and interpreting interaction. Newbury Park, CA: Sage.

Bishop, G.D. (1991). Understanding the understanding of illness. In J.A. Skelton and R.T. Croyle (Eds.), Mental representation in health and illness (pp. 32-59). New York: Springer.

Boney McCoy, S., Gibbons, F.X., Reis, T.J., Gerrard, M., Luus, C.A.E. and Wald Sufka, A. von (1992). Perceptions of smoking risk as a function of smoking status. Journal of Behavioral Medicine, 15, 469-488.

Fontaine, K.R. and Smith, S. (1995). Optimistic bias in cancer risk perception: A cross-national study. Psychological Reports, 77, 143-146.

Gerrard, M., Gibbons, F.X. and Benthin, A.C. (1996). A longitudinal study of the reciprocal nature of risk behaviors and cognitions in adolescents: What you do shapes what you think, and vice versa. Health Psychology, 15, 344-354.

Gerrard, M., Gibbons, F.X. and Bushman, B.J. (1996). The relation between perceived vulnerability to HIV and precautionary sexual behavior. Psychological Bulletin, 119, 390-409.

Gibbons, F.X. and Gerrard, M. (1995). Predicting young adults' health risk behavior. Journal of Personality and Social Psychology, 69, 505-517.

Gibbons, F.X., Gerrard, M., Lando, H.A. and McGovern, P.G. (1991). Social comparison and smoking cessation: The role of the 'typical smoker'. Journal of Experimental Social Psychology, 27, 239-258.

Hansen, W.B. and Malotte, C.K. (1986). Perceived personal immunity: The development of beliefs about susceptibility to the consequences of smoking. Preventive Medicine, 15, 363-372.

Harris, P. and Middleton, W. (1994). The illusion of control and optimism about health: On being less at risk but no more in control than others. The British Journal of Social Psychology, 33, 369-378.

Junge, B. (1995). Tabak [Tobacco consumption]. In Deutsche Hauptstelle gegen die Suchtgefahren (Ed.), Jahrbuch der Sucht 1996 [Yearbook of addictions 1996] (pp. 69-83). Neuland, Germany: Geesthacht.

Kahneman, D. and Tversky, A. (1972). Subjective probability: A judgment of representativeness. Cognitive Psychology, 3, 430-454.

Lee, C. (1989). Perceptions of immunity to disease in adult smokers. Journal of Behavioral Medicine, 12, 267-277.

McKenna, F.P., Warburton, D.M. and Winwood, M. (1993). Exploring the limits of optimism: The case of smokers' decision making. British Journal of Psychology, 84, $389-394$.

Moore, S.M. and Rosenthal, D.A. (1992). Australian adolescents' perceptions of health-related risks. Journal of Adolescent Research, 7, 177-191.

Perloff, L.S. and Fetzer, B.K. (1986). Self-other judgments and perceived vulnerability to victimization. Journal of Personality and Social Psychology, 50, 502-510. 
Prochaska, J.O. (1994). Strong and weak principles for progressing from precontemplation to action on the basis of twelve problem behaviors. Health Psychology, 13, 47-51.

Reppucci, J.D., Revenson, T.A., Aber, M. and Reppucci, N.D. (1991). Unrealistic optimism among adolescent smokers and nonsmokers. Journal of Primary Prevention, 11, 227-236.

Schwarzer, R. (1992). Self-efficacy in the adoption and maintenance of health behaviors: Theoretical approaches and a new model. In R. Schwarzer (Ed.), Self-efficacy: Thought control of action (pp. 217-242). Washington, DC: Hemisphere.

Schwarzer, R. (1994). Optimism, vulnerability, and self-beliefs as health-related cognitions: A systematic overview. Psychology and Health, 9, 161-180.

Schwarzer, R. and Fuchs, R. (1995). Changing risk-behaviors and adapting healthbehaviors: The role of self-efficacy beliefs. In A. Bandura (Ed.), Self-efficacy in changing societies (pp. 259-288). New York: Cambridge University Press.

Segerstrom, S.C., McCarthy, W.J., Caskey, N.H., Gross, T.M. and Jarvik, M.E. (1993). Optimistic bias among cigarette smokers. Journal of Applied Social Psychology, 23, 1606-1618.

Strecher, V.J., Kreuter, M.W. and Kobrin, S.C. (1995). Do cigarette smokers have unrealistic perceptions of their heart attack, cancer, and stroke risk? Journal of Behavioral Medicine, 18, 45-54.

Sutton, S. (1995). Unrealistic optimism in smokers: Effect of receiving information about the average smoker. Manuscript submitted for publication. University of London, Institute of Psychiatry.

Taylor, S.E. (1989). Positive illusions: Creative self-deception and the healthy mind. New York: Basic Books.

Taylor, S.E. (1994). Health psychology (3rd ed.). New York: McGraw-Hill.

Taylor, S.E. and Brown, J.D. (1988). Illusion and well-being: A social psychological perspective on mental health. Psychological Bulletin, 103, 193-210.

Taylor, S.E. and Brown, J.D. (1994). Positive illusion and well-being revisited: Separating fact from fiction. Psychological Bulletin, 116, $21-27$.

Taylor, S.E. and Gollwitzer, P.M. (1995). Effects of mindsets on positive illusions. Journal of Personality and Social Psychology, 69, 213-226.

Velde, F.W. van der, Pligt, J. van der and Hoykaas, C. (1994). Perceiving AIDS-related risk: Accuracy as a function of differences in actual risk. Health Psychology, 13, 25-33.

Warner, K.E., Halpern, M.T. and Giovino, G.A. (1994). Differences by education in smoker/non-smoker beliefs about the dangers of smoking. Health Education Research, 9, 139-143.

Weinstein, N.D. (1980). Unrealistic optimism about future life events. Journal of Personality and Social Psychology, 39, 806-820.

Weinstein, N.D. (1982). Unrealistic optimism about susceptibility to health problems. Journal of Behavioral Medicine, 5, 441-460.

Weinstein, N.D. (1984). Why it won't happen to me: Perceptions of risk factors and illness susceptibility. Health Psychology, 3, 431-457.

Weinstein, N.D. (1989a). Effects of personal experience on self-protective behavior. Psychological Bulletin, 105, 31-50.

Weinstein, N.D. (1989b). Perceptions of personal susceptibility to harm. In V.M. Mays, G.W. Albee, and S.F. Schneider (Eds.), Primary prevention of AIDS (pp. 142-167). Newbury Park, CA: Sage.

Weinstein, N.D. (1996). Unrealistic optimism: Present and future. Journal of Social and Clinical Psychology, 15, 1-8.

Welkenhuysen, M., Evers-Kiebooms, G., Decruyenaere, M. and Berghe, H. van den (1996). Unrealistic optimism and genetic risk. Psychology and Health, 11, 479-492. 